\title{
A concept analysis of mentoring in nursing leadership
}

\author{
Alexis Kathleen Hodgson, Judith M. Scanlan \\ University of Manitoba, Winnipeg, Canada \\ Email: alexiskathleenhodgson@gmail.com
}

Received 2 June 2013; revised 2 July 2013; accepted 10 August 2013

Copyright (c) 2013 Alexis Kathleen Hodgson, Judith M. Scanlan. This is an open access article distributed under the Creative Commons Attribution License, which permits unrestricted use, distribution, and reproduction in any medium, provided the original work is properly cited.

\begin{abstract}
Attention in the literature has been given to the critical state of nursing leadership development. There is a need to identify effective ways to sustain and develop nursing leaders. Mentoring has been identified as an invaluable tool to attract and retain new nurse leaders. Examining the concept of mentoring in nursing leadership provides a greater understanding of its importance in today's healthcare system. The concept of mentoring will be analyzed using the framework developed by Walker and Avant. A literature review was conducted to examine the current usage of the concept of mentoring. Consistent with Walker and Avant's framework, defining attributes, antecedents, and consequences of mentoring have been identified. Further illustration of this concept is provided by describing model, borderline, related, and contrary cases. Demonstrating the occurrence of the concept of mentoring, Empirical referents will also be explored.
\end{abstract}

Keywords: Mentoring; Nursing Leadership; Leadership Development; Concept Analysis

\section{INTRODUCTION}

Although attention in the literature has been given to the critical state of nursing leadership development, there is a need to identify effective ways to sustain and develop nursing leaders. The concept of mentoring has been identified as a way to address this need. McCloughen, O'Brien, and Jackson [1] identified mentorship and leadership as an "integrated phenomena" (p. 97). However, the understanding of the concept of mentoring in nursing is limited [2]. The purpose of this paper is to examine the concept of mentoring, and its relevance to nursing leaders.

This concept analysis will be guided by the framework outlined by Walker and Avant [3] which includes defining the concept, identifying usage of the concept, and a literature review. Definitions of the concept and a review of the literature will examine the current use of the concept and the critical attributes associated with mentoring. Related terms will be described providing additional clarity of the concept. Cases will be presented, and the antecedents and consequences of mentoring will be discussed. Lastly, empirical referents that indicate the presence of the concept will be explored [3].

\section{CONCEPT DEFINITION}

The Oxford English Dictionary [4] defines mentoring as the action of advising or training another person, usually a less experienced colleague. There is no single definition of mentoring [5]; however, there is a shared understanding that mentoring is a process in which a person who is experienced, wise, and trusted guides an inexperienced individual [6]. The act of mentoring has become popular, despite the difficulty to clearly define due to the subjective nature of the personal relationships of those involved in mentoring. The term mentor dates back to Greek mythology and Homer's Odyssey. Mentor was the older, counsellor, and friend of Odysseus who entrusted the care of his son to Mentor [7,8].

Within the nursing profession, mentoring is described as a valued relationship [6] a nurturing process in which a more experienced person supports the professional growth and career development of another [9]. Ali and Panther [10] stress that mentoring is considered an important role that "every nurse has to assume" (p. 35). The act of mentoring leads to an ongoing relationship in all domains of nursing practice, administration, education, research, and direct care [11]. Mentoring is a confidential, supportive relationship, in which a more experienced person guides a less experienced person with a goal of reaching their full potential [5,12]. A personal connection, mutual trust, and respect between two people are crucial for a successful mentoring relationship [2,13]. 


\section{LITERATURE REVIEW}

History suggests that mentoring has been used in nursing as far back as Florence Nightingale [14-16]. Nonetheless, mentoring is a relatively new concept in nursing, appearing in the literature in the 1980's [10,17]. While long used in other professions, mentoring now is gaining attention and acceptance as an effective strategy for nursing professional development $[13,18]$. The literature supports the need to conduct this concept analysis, as the most recent concept analyses of mentoring in nursing were published approximately 20 years ago $[19,20]$ The profession of nursing has drastically changed over the past 20 years, and a current concept analysis of mentoring based on relevant and current literature is beneficial to the profession and to development of nurse leaders.

To gain an understanding of the true nature of the concept, a broad search not limited to nursing literature was conducted [3]. Definitions and uses of the concept of mentoring were reviewed outside of nursing in the disciplines of business management, vocational behaviour, education, library sciences, social sciences, and medicine. A literature review was conducted using databases of Pub Med, CINAHL, AbInform, Scopus, and the Cochrane Institute.

Mentoring is a multi-disciplinary concept [8]. Academic medicine describes mentoring as a vibrant, fulfilling relationship between an established faculty member and a new faculty member preferably in the same discipline [21]. In academe, mentoring helps scholars work independently while navigating the culture and supporting contributions to research and education [22]. The impact of mentoring on career advancement has been extensively studied in business [23]. Wang [24] stated that "fledging professionals" are the beneficiaries of mentoring processes.

Carroll [25] and Daniels [26] argue that understanding the concept of mentoring is critical in nursing leadership and management. Without an in-depth understanding of the concept of mentoring, healthcare organizations cannot increase knowledge development [2] or develop effective leadership programs. Nurse managers work with large spans of control, often with minimal support and guidance, contributing to difficulty in recruiting and retaining new nurse managers [27]. A strong support system and mentor is a key aspect in the transition to a nurse leader role [28]. Attracting new nurse leaders is a critical issue that needs to be addressed by healthcare organizations and the nursing profession [29-32]. Healthcare organizations and nursing leaders must recognize and support the use of mentoring in succession planning. Mentoring is used to identify, nurture, support, and develop new nurse leaders [13,33-35].

\section{USES OF THE CONCEPT}

Throughout the literature the term mentoring is used to define a relationship between two people, with a goal of furthering the mentee's career and professional development [36-38]. The concept of mentoring is used to describe a form of employee development in which a trusted person uses his/her experience to offer guidance, encouragement, career advice, and support to another person. Mentoring impacts personal and professional skills and provides contextual feedback [35,39].

\section{CHARACTERISTICS OF MENTORING}

The Canadian Nurses Association [11] state "mentoring involves a voluntary and mutually beneficial relationship" (p. 18). Wroten and Waite [40] describe mentoring as "purposeful activities that facilitate career development, personal growth, caring, empowerment, and nurturance that is integral to nursing practice and leadership” (p. 106). Mentoring relationships can vary across settings and be formal or informal in nature [13]. Mentoring is a process that develops over time [41], a complex, reciprocal relationship between a mentor and mentee that has potential for successful personal and professional development [42-45].

Mentoring in nursing leadership and management can be described simply as leaders developing leaders [46]. Experienced nurse leaders, who share their tacit knowledge, support the new nurse leader when making difficult decisions. Support for the new nurse leader assists in attracting other nurse leaders to assume management roles. Mentoring is useful in developing the skill set of the mentees [47] as the mentor recognizes the potential of the mentee and guides and supports his/her development from experience [42,48].

The nature and quality of the relationship is fundamental to the process of mentoring $[17,46]$. At the core of the relationship are two people who see value and meaning in eachother and want to be in a relationship together [13,49,50]. Barker [42] and Young [45] describe mentoring as a relationship that is based on mutual respect and common goals. Mentoring involves the sharing of valuable tacit knowledge $[43,45]$ through effective engaging, and respectful communication [42,51].

Mentors are approachable, knowledgeable, honest, friendly, patient, experienced, enthusiastic, and willing to spend time with the mentee $[10,15,17,43,44,47,50,52,53]$. Mentors have astrong belief in the mentee's capability $[13,18]$; they challenge, support, and encourage a mentee [54-56]. A mentee must be willing to learn, be career committed, competent, and have strong self- identity and initiative $[13,57]$.

\section{RELATED TERMS}

Precepting, coaching, role modeling, and networking are 
terms associated with mentoring [20,58,59]. Precepting is an orientation technique that is clinically focusedwith assigned relationships between experienced and new staff [19] and lasts for short or specified periods of time $[7,60]$. Precepting usually includes formal assessments or evaluations [42,53]. Coaching is a term that is similar to mentoring in that an individual is provided with feedback, receives support, and guidance [54,59]. Coaching involves a more formal relationship with the coach typically not selected by the mentee [61]. The act of coaching is focused on behaviours and the development of certain skills in a current role; whereas mentoring is noted to focus on supporting career and interpersonal development, rather than behaviours [41,61-63].

Networking is described as a way of providing advice, support, and feedback to individuals, offering unique strategies to balance and deal with organizational and home life issues [63]. Networking requires no relationship and can be done by the employee alone, for example an employee attends work functions to meet fellow colleagues and supervisors.

Role modeling is a related term in which an individual internalizes and emulates behaviour, values, or appearances of another [19]. Unlike mentoring, role modeling is passive in nature and does not involve a relationship between two people.

\section{DEFINING ATTRIBUTES}

Defining attributes are characteristics of a concept that occur throughout the literature and help to further define the concept [3]. Based on the literature search conducted for this concept analysis, four defining attributes are used to describe mentoring. They are: 1 ) relationship between two individuals with differing levels of experience, 2) relationship based on mutual respect and common goals, 3) demonstrated willingness by mentor and mentee to engage in the relationship, and 4) sharing of knowledge.

\section{CASES}

Walker and Avant [3] suggest that the use of cases (model, borderline, contrary, and related) assist in further illustrating the concept. The cases may or may not contain all of the defining attributes such as those described above. The inclusion of these cases in a concept analysis enhances the understanding the concept of mentoring.

\subsection{Model Case}

Sally, a clinical resource nurse, wants to pursue a career in administration and nursing leadership. She feels comfortable seeking guidance from her current manager, Claire. Claire has extensive experience in nursing administrationand is well respected amongst her peers.
She demonstrates a leadership style that facilitates an open caring relationship with Sally. Aware of Sally's career goals, Claire encourages and supports Sally's growth and development by sharing her leadership knowledge. Their relationship demonstrates engaging, respectful communication.

This model case contains all of the critical attributes. Sally and Claire demonstrate a willingness to participate in a relationship. Claire shares her knowledge and experience with Sally, supporting her career goals and ambition. They demonstrate respect and understand the common goal of furthering Sally’s career.

\subsection{Borderline Case}

Kevin, a clinical resource nurse, is interested in leadership and wants to pursue a career in nursing administration. Kevin's current manager, Claire has extensive experience in nursing leadership and is well respected amongst her peers. Aware of Kevin's career goals, Claire attempts to encourage and support Kevin's growth and development by sharing her leadership knowledge. She demonstrates a leadership style that would facilitate an open caring relationship with Kevin. Kevin, however, is not comfortable seeking guidance from Claire. He is enrolled in graduate education and believes that he will gain knowledge regarding nursing leadership through his studies.

This case lacks Kevin's willingness to participate in a mentoring relationship. Although the other critical attributes that define mentoring are present, without participation by both the mentor and mentee, the relationship cannot be defined as a mentoring.

\subsection{Related Case}

Sarah is a new nurse on a surgical ward. She has been assigned to a preceptor, Marcella. Marcella is a nurse with 10 years of experience, and will work closely with Sarah to assist in her orientation to her new position. Sarah will work every shift with Marcella, with ongoing formal evaluation in 12 weeks.

This case illustrates the related concept of precepting [19]. However, precepting is a time-limited, orientation process with assigned individuals. Precepting differs from mentoring in which participants choose each other; there is no time limit and no formal evaluations.

\subsection{Contrary Case}

Lisa is a new nurse, she feels overwhelmed and "scared" in her new role and of her new responsibilities. She approaches Tim, a senior nurse and asks for help. His response is "I am sorry you are feeling that way. You will get over it” and walks away.

This case is simply not mentoring. The actions of the 
experienced nurse is a clear contrast to mentoring which includes a respectful relationship in which knowledge is shared to further the goal of the mentee's development.

\section{ANTECEDENTS TO MENTORING}

Antecedents are events or incidents that happen prior to the occurrence of the concept [3]. The most obvious antecedent of mentoring is that a mentor and mentee are required. A mentoring relationship does not exist without a mentor and mentee [20]. The act of mentoring begins with mentors and mentees self-selecting each other and establishing a relationship [36,61]. Often the initiation of the relationship is driven by the mentee [15,27,53,54]. Common interests and the right chemistry lead to successful relationships [18,49].

As a career development tool, health care organizations must believe in the outcomes of mentoring. Mentoring is the responsibility of organizations to support the mentor and the mentee. An organization that supports and encourages mentoring enhances success in matching and mentoring outcomes[45,46,52,64].

\section{CONSEQUENCES OF MENTORING}

Consequences of mentoring occur after the concept is present; that is outcomes of the concept [3]. The experience of mentoring allows the mentee to gain insight into and develop leadership skills [65]. Mentoring is associated with increased job satisfaction and retention which is beneficial for the mentee, mentor, organization, and nursing profession $[14,38,41,46,49,52,66]$. Not only do the individuals involvedin the mentoring relationship benefit, but the organization and ultimately the patient benefit $[7,16,27,49,67]$. Mentoring empowers mentors and mentees [68], and empowerment enhances employees motivation and professional development [18]. By embracing mentoring relationships, a culture and workplace is created in which nurses want to come to work [7]. The newly empowered nurse has high self esteem and, in turn, mentors new staff and the cycle continues $[18,22,53]$.

\section{EMPIRICAL REFERENTS}

Empirical referents indicate that the concept has occurred [3]. Walker and Avant state that "empirical referents are classes or categories of actual phenomena that by their existence or presence demonstrate the occurrence of the concept itself” (p. 71). There is a plethora of tools that have been developed to measure both the career and psychosocial functions of mentoring. The wide variation in what each tool specifically aims to measure is presumably due to the subjective nature of mentoring. A Mentoring Function Questionnaire developed by Scandura et al. [48] provides an example of areas or in- dicators of mentoring that can be empirically measured.

\section{CONCLUSION}

The recruitment and retention of new nursing leaders are affected by the seemingly overwhelming expectations and responsibilities of current formal nursing leadership roles. Nurses need to continue to step into formal leadership roles, ensuring that the nursing profession successfully rises to meet the challenges and needs of the healthcare system and the people we serve. The nursing profession needs to commit to and embrace the concept of mentoring to provide new nurse leaders with supportive environments, in which they can grow and flourish $[9,38,52,69]$. Examining the concept of mentoring in nursing leadership provides a greater understanding of its importance in today's healthcare system.

Mentoring is an invaluable tool for the future of nursing leadership and should be highly regarded as a way to promote and support nursing leaders; a mechanism critical to the future of the nursing profession [70]. Mentoring must be recognized and supported by healthcare organizations as a critical succession planning strategy to attract and retain new nurse leaders.

\section{REFERENCES}

[1] McCloughen, A., O’Brien, L. and Jackson, D. (2011) Nurse leader mentor as a mode of being: Findings from an Australian Hermeneutic Phenomenological Study. Journal of Nursing Scholarship, 43, 97-104. doi:10.1111/j.1547-5069.2010.01377.x

[2] Thomka, L. (2007) Mentoring and its impact on intellectual capital: Through the eyes of the mentee. Nursing Administration Quarterly, 31, 22-26. doi:10.1097/00006216-200701000-00008

[3] Walker, L. and Avant, K. (2005) Strategies for theory construction in nursing. 4th Edition, Appleton \& Lange, Norwalk.

[4] Oxford Dictionary Mentoring (2001) Oxford English Dictionary. 3rd Edition. http://www.oed.com/view/Entry/251875

[5] Mentoring (2008) Key Concepts in Nursing. Sage, London. Credo Reference. http://www.credoreference.com

[6] Short, J.D. (2002) Mentoring: Career enhancement of occupational \& environmental health nurses. American Association of Occupational Health Nurses, 50, 135.

[7] Block, L.M., Claffey, C., Korow, M.K. and McCaffrey, R. (2005) The value of mentorship within nursing organizations. Nursing Forum, 40, 134-140. doi:10.1111/j.1744-6198.2005.00026.x

[8] Gentry, W.A., Weber, T.J. and Sadri, G. (2008) Examining career-related mentoring and managerial performance across cultures: A multilevel analysis. Journal of Vocational Behaviour, 72, 241-253. doi:10.1016/j.jvb.2007.10.014 
[9] Tahan, H. (2002) Journey to professional transformation: A mentoring experience. Seminars for Nurse Managers, 10, 140-143.

[10] Ali, P.A. and Panther, W. (2008) Professional development and the role of mentorship. Nursing Standard (Royal College of Nursing (Great Britain)), 22, 35-39.

[11] Canadian Nurses Association (2004) Achieving excellence in profession practice: A guide to preceptorship and mentoring. Canadian Nurses Association, Ottawa. www.cna-aiic.ca

[12] Mentoring (2009) BUSINESS: The ultimate resource. A\&C Black, London. http://www.credoreference.com

[13] McCloughen, A., O’Brien, L. and Jackson, D. (2009) Esteemed connection: Creating a mentoring relationship for nurse leadership. Nursing Inquiry, 16, 326-336. doi:10.1111/j.1440-1800.2009.00451.x

[14] Barton, D.S., Gowdy, M. and Hawthorne, B.W. (2005) Mentorship programs for novice nurses. Nurse Leader, 3, 41-44. doi:10.1016/j.mnl.2005.06.005

[15] Metcalfe, S.E. (2010) Educational innovation: Collaborative mentoring for future nursing leaders. Creative Nursing, 16, 167-170. doi:10.1891/1078-4535.16.4.167

[16] Owens, J.K. and Patton, J.G. (2003) Take a chance on nursing mentorships. Enhance leadership with this winwin strategy. Nursing Education Perspectives, 24, 198204.

[17] Andrews, M. and Wallis, M. (1999) Mentorship in nursing: A literature review. Journal of Advanced Nursing, 29, 201-207. doi:10.1046/j.1365-2648.1999.00884.x

[18] Lee, L.A. (2000) Buzzwords with a basis: Motivation, mentoring, and empowerment aren't just management jargon-They're resources you use every day. Nursing Management, 31, 24-28.

doi:10.1097/00006247-200010000-00018

[19] Stewart, B.M. and Krueger, L.E. (1996) An evolutionary concept analysis of mentoring in nursing. Journal of Professional Nursing: Official Journal of the American Association of Colleges of Nursing, 12, 311-321. doi:10.1016/S8755-7223(96)80011-1

[20] Yoder, L. (1990) Mentoring: A concept analysis. Nursing Administration Quarterly, 15, 9-19. doi:10.1097/00006216-199001510-00005

[21] Rustgi, A.K. and Hecht, G.A. (2011) Mentorship in academic medicine. Gastroenterology, 141, 789-792. doi:10.1053/j.gastro.2011.07.024

[22] Pomeroy, E.C. and Steiker, L.H. (2011) Paying it forward: On mentors and mentoring. Social Work, 56, 197-199. doi:10.1093/sw/56.3.197

[23] Adeniran, R., Bhattacharya, A. and Adeniran, A. (2012) Professional excellence and career advancement in nursing: A conceptual framework for clinical leadership development. Nursing Administration Quarterly, 36, 41-51. doi:10.1097/NAQ.0b013e31823b0fec

[24] Wang, H. (2001) Academic mentorship: An effective professional development strategy for medical reference librarians. Medical Reference Services Quarterly, 20, 2331. doi:10.1300/J115v20n02 03
[25] Carroll, K. (2004) Mentoring: A human becoming perspective. Nursing Science Quarterly, 17, 318-322. doi:10.1177/0894318404269370

[26] Daniels, M. (2004) Mentoring: Link to the future. Reflections on Nursing Leadership, 30, 24-25.

[27] Waters, D., Clarke, M., Ingall, A.H. and Dean-Jones, M. (2003) Evaluation of a pilot mentoring programme for nurse managers. Journal of Advanced Nursing, 42, 516526. doi:10.1046/j.1365-2648.2003.02651.x

[28] Shifflet, V.L. and Moyer, A.R. (2010) Staff nurse to nurse leader: Steps for success. MedSurg Nursing, 19, 252-248.

[29] Jeans, M. (2006) Strengthening mentorship for leadership development. Nursing Leadership, 19, 28-29.

[30] Rudan, V.T. (2002) Where have all the nursing administration students gone? Issues and solutions. The Journal of Nursing Administration, 32, 185-188. doi:10.1097/00005110-200204000-00006

[31] Sherman, R., Bishop, M., Eggenberge, T. and Karden, R. (2007) Development of a leadership competency model. Journal of Nursing Administration, 37, 85-94. doi:10.1097/00005110-200702000-00011

[32] VanOyen-Force, M. (2005) The relationship between effective nurse managers and nursing retention. The Journal of Nursing Administration, 35, 336-341.

[33] Connors, S., Dunn, R., Devine, K. and Osterman, C. (2007) Strategies for cultivating nursing leadership. Nurse Leader, 5, 26-32. doi:10.1016/j.mnl.2007.07.005

[34] Milton, C. (2004) The ethics of personal integrity in leadership and mentorship: A nursing theoretical perspective. Nursing Science Quarterly, 17, 116-120. doi:10.1177/0894318404263261

[35] Nash, S. and Scammel, J. (2010) Skills to ensure success in mentoring and other workplace learning approaches. Nursing Times, 106, 17-20.

[36] Gardner, E.A. and Schmidt, C.K. (2007) Implementing a leadership course and mentor model of students in the national student nurses' association. Nurse Educator, 32, 178-182. doi:10.1097/01.NNE.0000281081.48925.11

[37] Gershenson, T.A., Moravick, D.A., Sellman, E. and Somerville, S. (2004) Career scope: Northeast. Expert to novice: A nurse leader's evolution. Nursing Management, 35, 49-52. doi:10.1097/00006247-200406000-00017

[38] Race, T.K. and Skees, J. (2010) Changing tides: Improving outcomes through mentorship on all levels of nursing. Critical Care Nursing Quarterly, 33, 163-176.

[39] Cho, C.S., Ramanan, R.A. and Feldman, M.D. (2011) Defining the ideal qualities of mentorship: A qualitative analysis of the characteristics of outstanding mentors. The American Journal of Medicine, 124, 453-458. doi:10.1016/j.amjmed.2010.12.007

[40] Wroten, S.J. and Waite, R. (2009) A call to action: Mentoring within the nursing profession-A wonderful gift to give and share. The ABNF Journal, 20, 106-108.

[41] Fielden, S.L., Davidson, M.J. and Sutherland, V.J. (2009) Innovations in coaching and mentoring: Implications for nurse leadership development. Health Services Manage- 
ment Research, 22, 92-99. doi:10.1258/hsmr.2008.008021

[42] Barker, E.R. (2006) Mentoring-A complex relationship. Journal of the American Academy of Nurse Practitioners, 18, 56-61. doi:10.1111/j.1745-7599.2006.00102.x

[43] Harvey, M., McIntyre, N., Heames, J.T. and Moeller, M. (2009) Mentoring global female managers in the global marketplace: Traditional, reverse, and reciprocal mentoring. International Journal of Human Resource Management, 20, 1344-1361. doi:10.1080/09585190902909863

[44] Hodges, B. (2009) Factors that can influence mentorship relationships. Paediatric Nursing, 21, 32-35.

[45] Young, L.E. (2009) Mentoring new nurses in stressful times. Canadian Operating Room Nursing Journal, 27, 6-7, 14-5, 28-30.

[46] Gallo, K. (2007) The new nurse manager: A leadership development program paves the road to success. Nurse Leader, 5, 28-32. doi:10.1016/j.mnl.2007.05.004

[47] LaFleur, A.K. and White, B.J. (2010) Appreciating mentorship: The benefits of being a mentor. Professional Case Management, 15, 305-313. doi:10.1097/NCM.0b013e3181eae464

[48] Scandura, T.A. and Williams, E.A. (2004) Mentoring and transformational leadership: The role of supervisory career mentoring. Journal of Vocational Behaviour, 65, 448-468. doi:10.1016/j.jvb.2003.10.003

[49] Kanaskie, M.L. (2006) Mentoring-A staff retention tool. Critical Care Nursing Quarterly, 29, 248-252.

[50] Tourigny, L. and Pulich, M. (2005) A critical examination of formal and informal mentoring among nurses. The Health Care Manager, 24, 68-76.

[51] Anderson, L. (2011) A learning resource for developing effective mentorship in practice. Nursing Standard, 25, 48-56.

[52] Grindel, C.G. (2003) Mentoring managers. Nephrology Nursing Journal, 30, 517-522.

[53] Huybrecht, S., Loeckx, W., Quaeyhaegens, Y., De Tobel, D. and Mistiaen, W. (2011) Mentoring in nursing education: Perceived characteristics of mentors and the consequences of mentorship. Nurse Education Today, 31, 274278. doi:10.1016/j.nedt.2010.10.022

[54] Pinkerton, S.E. (2003) Mentoring new graduates. Nursing Economics, 21, 202-203.

[55] Ulrich, B. (2009) Mentoring the next generation of nurse leaders. Nephrology Nursing Journal, 36, 11.

[56] Wilkins, A.M. and Ellis, G. (2004) Enhancing learning environments by maximising support to mentors. Nursing Times, 100, 36-38.

[57] Vance, C. (2000) Discovering the riches in mentor con- nections. Reflections on Nursing Leadership, 26, 24-25.

[58] DeCicco, J. (2008) Developing a preceptorship/mentorship model for home health care nurses. Journal of Community Health Nursing, 25, 15-25. doi:10.1080/07370010701836310

[59] Karsten, M., Baggot, D., Brown, A. and Cahill, M. (2010) Professional coaching as an effective strategy to retaining frontline managers. The Journal of Nursing Administration, 40, 140-144. doi:10.1097/NNA.0b013e3181d042c0

[60] Wagner, A.L. and Seymour, M.E. (2007) A model of caring mentorship for nursing. Journal for Nurses in Staff Development, 23, 201-213. doi:10.1097/01.NND.0000294926.14296.49

[61] DeCampli, P., Kirby, K.K. and Baldwin, C. (2010) Beyond the classroom to coaching: Preparing new nurse managers. Critical Care Nursing Quarterly, 33, 132-137.

[62] Renton, J. (2009) Coaching and mentoring: What they are and how to make the most of them. Bloomberg Press, New York.

[63] Tracey, C. and Nicholl, H. (2006) Mentoring and networking. Nursing Management, 12, 28-32.

[64] Colonghi, P. (2009) Mentoring? Take the LEAD. Nursing Management, 40, 15-17. doi:10.1097/01.NUMA.0000347406.42707.9c

[65] Bellack, J. and Morjikian, R. (2005) The RWJ executive nurse fellows program, Part 2. Journal of Nursing Administration, 35, 533-540. doi:10.1097/00005110-200512000-00007

[66] Bally, J.M.G. (2007) The role of nursing leadership in creating a mentoring culture in acute care environments. Nursing Economics, 25, 143-149.

[67] Donaldson, S., Ensher, E. and Grant-Vallone, E. (2000) Longitudinal examination of mentoring relationships on organizational commitment and citizenship behaviour. Journal of Career Development, 26, 233-249. doi:10.1177/089484530002600401

[68] Latham, C.L., Hogan, M. and Ringl, K. (2008) Nurses supporting nurses: Creating a mentoring program for staff nurses to improve the workforce environment. Nursing Administration Quarterly, 32, 27-39. doi:10.1097/01.NAQ.0000305945.23569.2b

[69] Kleinman, C.S. (2003) Leadership roles, competencies, and education: How prepared are our nurse managers? Journal of Nursing Administration, 33, 451-455.

[70] McCloughen, A., O’Brien, L. and Jackson, D. (2010) More than a vision: Imagination as an elemental characteristic of being a nurse leader-mentor. Advances in Nursing Science, 33, 285-296. 